\title{
SATB2-associated syndrome: characterization of skeletal features and of bone fragility in a prospective cohort of 19 patients
}

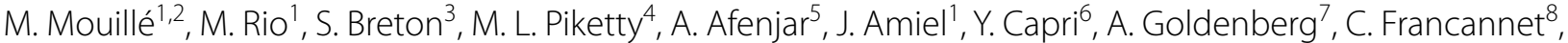 \\ C. Michot ${ }^{1,9}$, C. Mignot ${ }^{5,10}$, L. Perrin 6 , C. Quelin ${ }^{11}$, J. Van Gils ${ }^{12}$, G. Barcia ${ }^{13}$, V. Pingault ${ }^{13}$, G. Maruani $^{15}$, \\ E. Koumakis ${ }^{9,14}$ and V. Cormier-Daire ${ }^{1,9^{*}}$ (D)
}

\begin{abstract}
Background: Individuals with pathogenic variants in SATB2 display intellectual disability, speech and behavioral disorders, dental abnormalities and often features of Pierre Robin sequence. SATB2 encodes a transcription factor thought to play a role in bone remodeling. The primary aim of our study was to systematically review the skeletal manifestations of SATB2-associated syndrome. For this purpose, we performed a non-interventional, multicenter cohort study, from 2017 to 2018. We included 19 patients, 9 females and 10 males ranging in age from 2 to 19 yearsold. The following data were collected prospectively for each patient: clinical data, bone markers and calcium and phosphate metabolism parameters, skeletal X-rays and bone mineral density.

Results: Digitiform impressions were present in $8 / 14$ patients (57\%). Vertebral compression fractures affected 6/17 patients (35\%). Skeletal demineralization $(16 / 17,94 \%)$ and cortical thinning of vertebrae $(15 / 17)$ were the most frequent radiological features at the spine. Long bones were generally demineralized (18/19). The distal phalanges were short, thick and abnormally shaped. C-telopeptide (CTX) and Alkaline phosphatase levels were in the upper normal values and osteocalcin and serum procollagen type 1 amino-terminal propeptide (P1NP) were both increased. Vitamin D insufficiency was frequent (66.7\%).

Conclusion: We conclude that SATB2 pathogenic variants are responsible for skeletal demineralization and osteoporosis. We found increased levels of bone formation markers, supporting the key role of SATB2 in osteoblast differentiation. These results support the need for bone evaluation in children and adult patients with SATB2-associated syndrome (SAS).
\end{abstract}

Keywords: SATB2, Osteoporosis, ALP, Bone densitometry, X Ray, Demineralization

\section{Introduction}

SATB2-associated syndrome (SAS, Glass syndrome, OMIM612313) is a rare autosomal dominant condition [1-4], related to SATB2 mutations, characterized by intellectual disability, speech and behavioral disorders,

${ }^{*}$ Correspondence: valerie.cormier-daire@inserm.fr

${ }^{1}$ Clinical Genetics, Necker Enfants Malades Hospital, APHP, 149 rue de Sevres, Paris 75015, France

Full list of author information is available at the end of the article dental abnormalities such as malposition and macrodontia and often features of Pierre Robin sequence with cleft palate.

SATB2 (special AT rich sequence binding protein 2) is a highly conserved gene located on chromosome 2 , $(2 \mathrm{q} 33.1) ,191 \mathrm{~kb}[1,5]$. It encodes a transcription factor involved in craniofacial, central nervous system and skeletal development. SATB2 is also thought to play a role in bone remodeling [6-8]. SATB2 is a regulator of Osx which in turn, is responsible for the differentiation of original author(s) and the source, provide a link to the Creative Commons licence, and indicate if changes were made. The images or other third party material in this article are included in the article's Creative Commons licence, unless indicated otherwise in a credit line to the material. If material is not included in the article's Creative Commons licence and your intended use is not permitted by statutory regulation or exceeds the permitted use, you will need to obtain permission directly from the copyright holder. To view a copy of this licence, visit http://creativecommons.org/licenses/by/4.0/. The Creative Commons Public Domain Dedication waiver (http://creativeco mmons.org/publicdomain/zero/1.0/) applies to the data made available in this article, unless otherwise stated in a credit line to the data. 
mesenchymal cells into osteoblasts. Indeed, SATB2 plays a role at 2 levels firstly by blocking Hoxa2, which controls negatively the differentiation of mesenchymal progenitor cells to pro-osteoblasts and secondly by stimulating the differentiation of osteoblasts [9].

Several isolated clinical observations [10] have reported low bone mass, and/or bone fragility fracture in patients with SATB2 variants [4]. More recently, Zarate el al described low bone mass and early-onset fragility fractures in a retrospective series of 7 patients with SATB2 variants. In this series, elevated alkaline phosphatase levels were found in 5 individuals. To date, and to our knowledge, the characterization of skeletal involvement and of bone turnover markers in such patients has not yet been systematically collected in a prospective study. Moreover, the mechanism leading to early bone fragility is currently not completely understood. The aim of our study was to prospectively and systematically assess the skeletal manifestations observed in a cohort of 19 individuals with SAS, by the review of prevalent fractures and of skeletal X-rays. Patients underwent bone densitometry and had measurements of bone turnover markers as well as calcium and phosphate metabolism parameters.

\section{Subjects and methods}

We performed a non-interventional, multicenter cohort study, from 2017 to 2018. Patients were recruited and reviewed via the French Reference Center for Constitutional Bone Diseases (CRMR MOC).

\section{Patients}

19 patients with SATB2 pathogenic variants were included in the study. Consent was signed. Patient data were anonymized.

\section{Data collected}

The following data were collected for each patient: (1) Clinical data including age, gender, height, weight, medical history, history of fracture(s), vitamin D supplementation and other ongoing or past antiosteoporotic treatments. (2) Biological tests including serum total and ionized calcium, phosphorus, albumin, ionized calcium, 25 hydroxy-vitamin $\mathrm{D}, 1,25$ dihydroxy-vitamin $\mathrm{D}$, serum parathyroid hormone (PTH). Alkaline phosphatase levels (ALP), osteocalcin and serum procollagen type 1 aminoterminal propeptide (P1NP) were chosen to assess bone formation, and C-telopeptide (CTX) was chosen as a marker of bone resorption. Because normal reference range of these tests differ with patient age, and to compare the results between patients, results were displayed as an ULM, i.e. as the ratio of (patient value)/ (upper limit of normal range). Importantly, evaluation was performed in the absence of recent fracture $(<1$ year). Radiological evaluation was perfomed in the context of standard care evaluation of their skeletal dysplasia for all patients. They were reviewed by an experienced radiologist specialized in skeletal dysplasias from the CRMR-MOC. X-rays from spine, skull, long bones, and hands/feet were read independently of the clinical, biological and bone densitometry phenotype. Areal bone mineral density (aBMD) was measured by dual-energy X-ray absorptiometry (DXA) at the lumbar spine (L1-L4), total hip, and femoral neck using LUNAR or HOLOGIC equipment and software. Z-scores were used for data analysis.

\section{Statistical analysis}

Statistical analyses were performed using MedCalc Software (v11.6.1, MedCalc Software, Belgium) and Excel. Data are expressed as mean \pm standard deviation (SD) for continuous variables, and numbers and percentages for categorical variables. Comparisons of subgroup characteristics were performed using Mann-Whitney test for unpaired data. Comparisons of proportions were performed using a chi-square test. Spearman's rank correlation test was used to assess the relation between quantitative variables. For all analyses, a two-tailed $p$-value $<0.05$ was considered to indicate statistical significance.

\section{Data protection}

The study received approval from the committee for the protection of persons (CPP) on the 19/09/2017, file No 2017-102169-44, Reference CPP: 3534-NI. Data collection was in accordance with CNIL regulations and in accordance with the Helsinki declaration.

\section{Results}

In all, 9 females (47\%) and 10 males were included ranging in age from 2 to 19 years old. Extra skeletal features are summarized (Table 1). All mutations found were de novo, heterozygous and included partial or total deletion, missense and nonsense mutations (Table 2). None of our patients were taking medication.

\section{Skeletal features (Table 2)}

Nine/nineteen (47\%) patients had at least one reported clinical fracture. Of these 9 patients with fractures, one had a history of known vertebral fracture and 8 patients had peripheral fractures. Two patients had a history of more than one fracture, one of whom presented with a long bone deformity, vertebral and hip fractures and another patient with fractures of the humerus and clavicle. One patient had tibial bowing. Although the exact circumstances of fracture occurrence were not always known, they usually occurred following minor trauma and therefore were considered to be non-traumatic. 
Table 1 Extra skeletal features in the patients with SATB2 variants

\begin{tabular}{|c|c|c|c|c|c|}
\hline Patient & $\begin{array}{l}\text { Features of Pierre Robin } \\
\text { sequence }\end{array}$ & Dental abnormalities & Behavioral disorders & $\begin{array}{l}\text { Intellectual } \\
\text { disability }\end{array}$ & $\begin{array}{l}\text { Speech } \\
\text { disorders } \\
\text { Speech } \\
\text { delay }\end{array}$ \\
\hline SATB2-01-P1 & Yes & Hypodontia & No & Yes & Yes \\
\hline SATB2-01-P2 & No & Macrodontia & Autism spectrum disorder & Yes & Yes \\
\hline SATB2-01-P3 & No & Macrodontia & Autism spectrum disorder & Yes & Yes \\
\hline SATB2-01-P4 & No & Macrodontia & Autism spectrum disorder & Yes & Yes \\
\hline SATB2-01-P5 & No & Macrodontia & No & Yes & Yes \\
\hline SATB2-01-P6 & No & Macrodontia & No & Yes & Yes \\
\hline SATB2-01-P7 & Yes & Macrodontia & Autism spectrum disorder & Yes & Yes \\
\hline SATB2-01-P9 & No & Macrodontia & No & Yes & Yes \\
\hline SATB2-01-P10 & Yes & Macrodontia & Autism spectrum disorder & Yes & Yes \\
\hline SATB2-01-P11 & No & Macrodontia & No & Yes & Yes \\
\hline SATB2-01-P12 & Yes & Macrodontia & Autism spectrum disorder & Yes & Yes \\
\hline SATB2-01-P13 & Yes & Yes & No & Yes & Yes \\
\hline SATB2-02-P1 & No & Hypondotia & No & Yes & Yes \\
\hline SATB2-04-P1 & Yes & Yes & Yes & Yes & Yes \\
\hline SATB2-05-P1 & No & Yes & No & Yes & Yes \\
\hline SATB2-06-P1 & No & Yes & Autism spectrum disorder & Yes & Yes \\
\hline SATB2-06-P2 & No & Yes & Autism spectrum disorder & Yes & Yes \\
\hline SATB2-07-P1 & No & Yes & mild & Yes & Yes \\
\hline SATB2-08-P1 & No & No & No & Yes & Yes \\
\hline
\end{tabular}

None of the patients were receiving or had received bisphosphonates before the discovery of fractures.

\section{Skeletal evaluation \\ Calvaria (Table 3)}

Demineralization was observed in 10/14 (71\%) patients.

Thin calvarial bone was observed in 4/14 (29\%) patients, whereas a thick calvaria was observed in $1 / 14(7 \%)$ patients. Digitiform impressions were present in $8 / 14$ (57\%) patients.

\section{Spine (Fig. 1 and Tables 2, 3)}

Vertebral compression fractures were detected in 6/17 (35\%) patients. Skeletal demineralization (16/17, 94\%) and cortical thinning of vertebrae $(15 / 17,88 \%)$ were the most frequent features at the spine. Cortical collapse was seen in 2/17 (12\%) patients. Long bones (Fig. 1 and Tables 2, 3). Long bones were generally demineralized $(18 / 19,95 \%)$. The aspect of cortical bone was quite variable. No diaphyseal deformations or periosteal appositions were observed. A diaphyseal fracture of the femur was identified in one patient (5\%). Cortical thickness was variable: normal $(2 / 19,11 \%)$, thick $(7 / 19,37 \%)$, and thin in $3 / 19(16 \%)$ patients. Laminated bone cortex was frequently observed in 15/19 (79\%).

\section{Bone maturation (Fig. 1 and Tables 2, 3)}

Delayed ossification of carpal bones was noted in half of the patients aged 3 to 13 years-old $(9 / 18,50 \%)$, but 2 patients (11\%) aged 6 years to 13 years presented with advanced ossification of the carpal bones. Long bone striations were found at the metaphysis in 14/19 (68\%) of cases. Small epiphyses were noted in $12 / 19$ (63\%) of cases and ivories in $2 / 19$ (11\%) of the cases.

\section{Distal bones (Fig. 1)}

The distal phalanges were short, thick and abnormally shaped $(7 / 16,43 \%)$.

\section{Bone densitometry (Tables 2, 3)}

Bone densitometry was available for $13 / 19$ patients. Among these patients, $7 / 13$ (54\%) patients had a Z-score of $-2.0 \mathrm{SD}$ or lower (Z-score $\leq-2 \mathrm{SD})$ at the lumber spine or the total hip, and 5 / 13 (38\%) patients had a Z-score between -1 and -2 SD. Mean lumbar spine Z-score was-1.9 $\pm 1.1 \mathrm{SD}$. Mean hip Z-score was $-1.5 \pm 0.9 \mathrm{SD}$. Bone mineral density was in the normal range for 3 patients (7, 9 and 19 years old).

\section{Prevalence of osteoporosis (Table 3)}

Although only one patient reported a history of vertebral compression fracture, a total of 6 patients (35\%) 







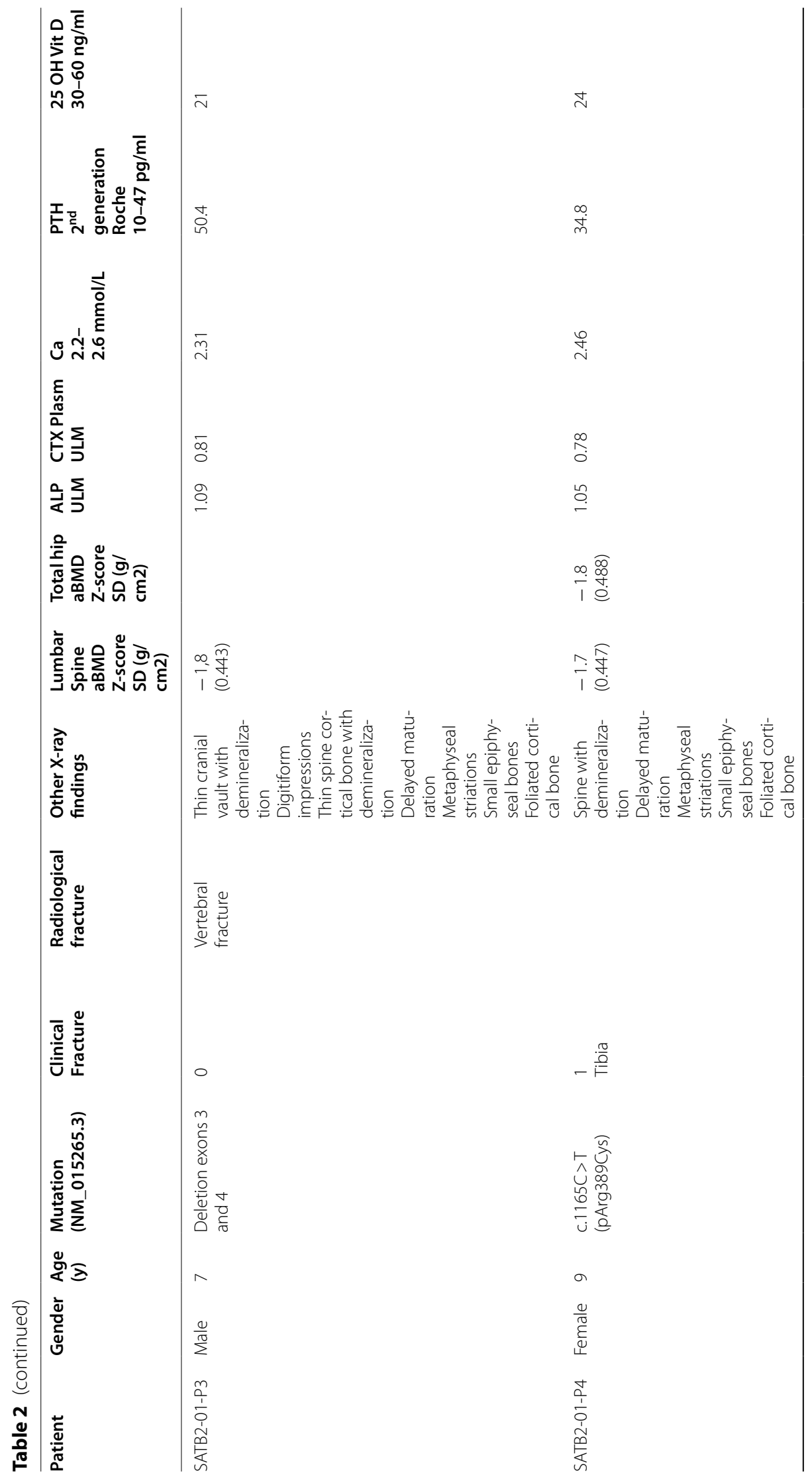




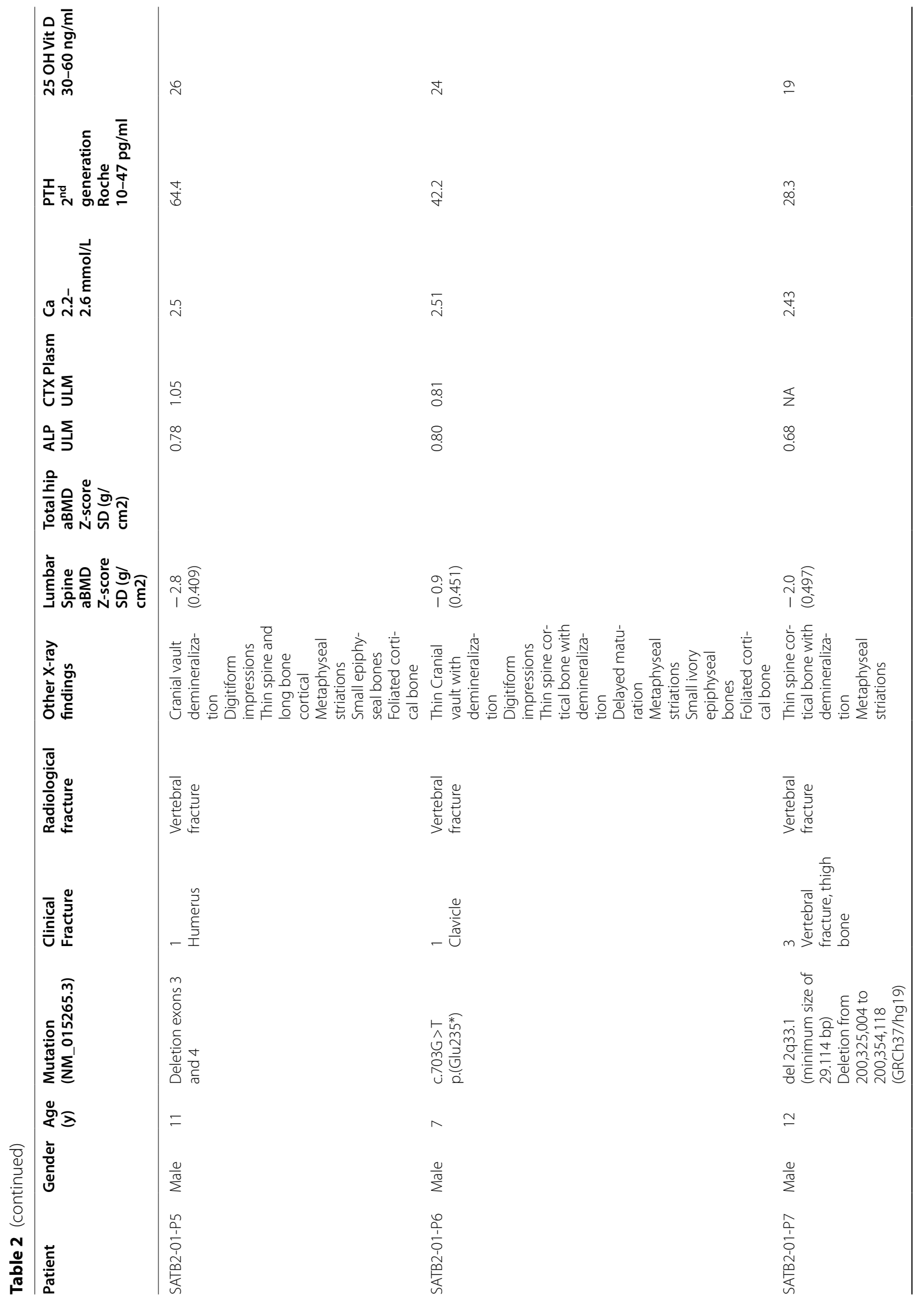




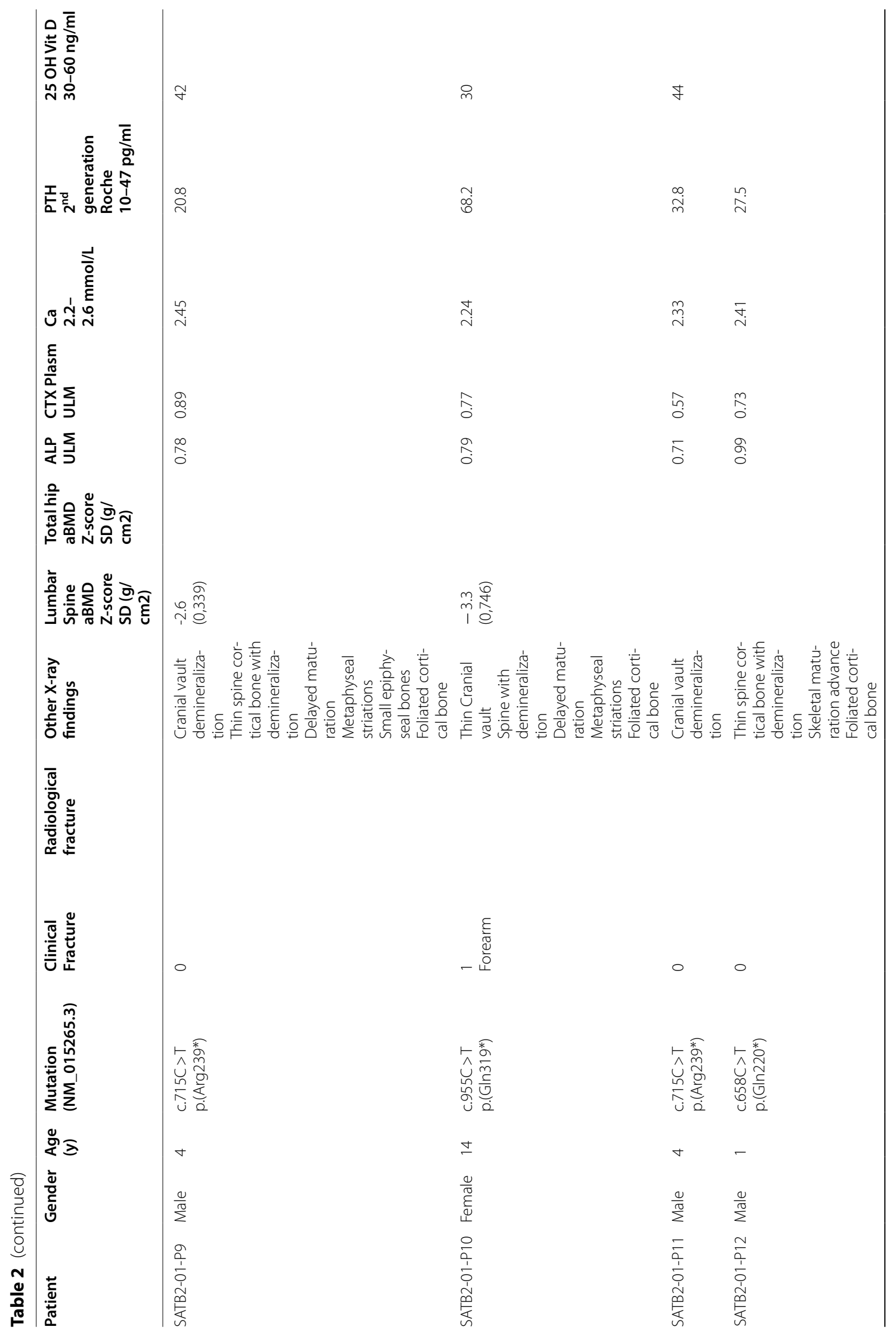




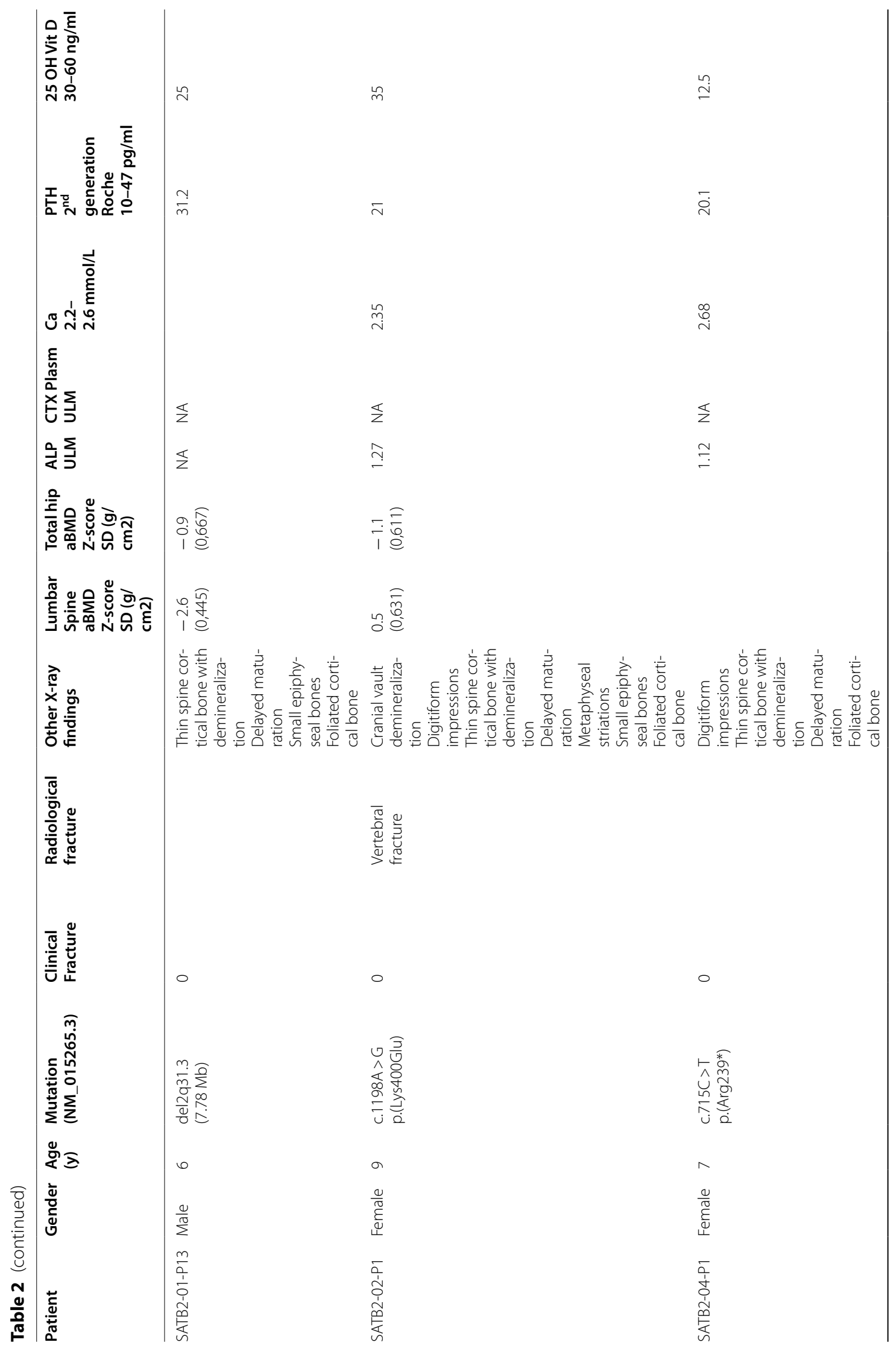




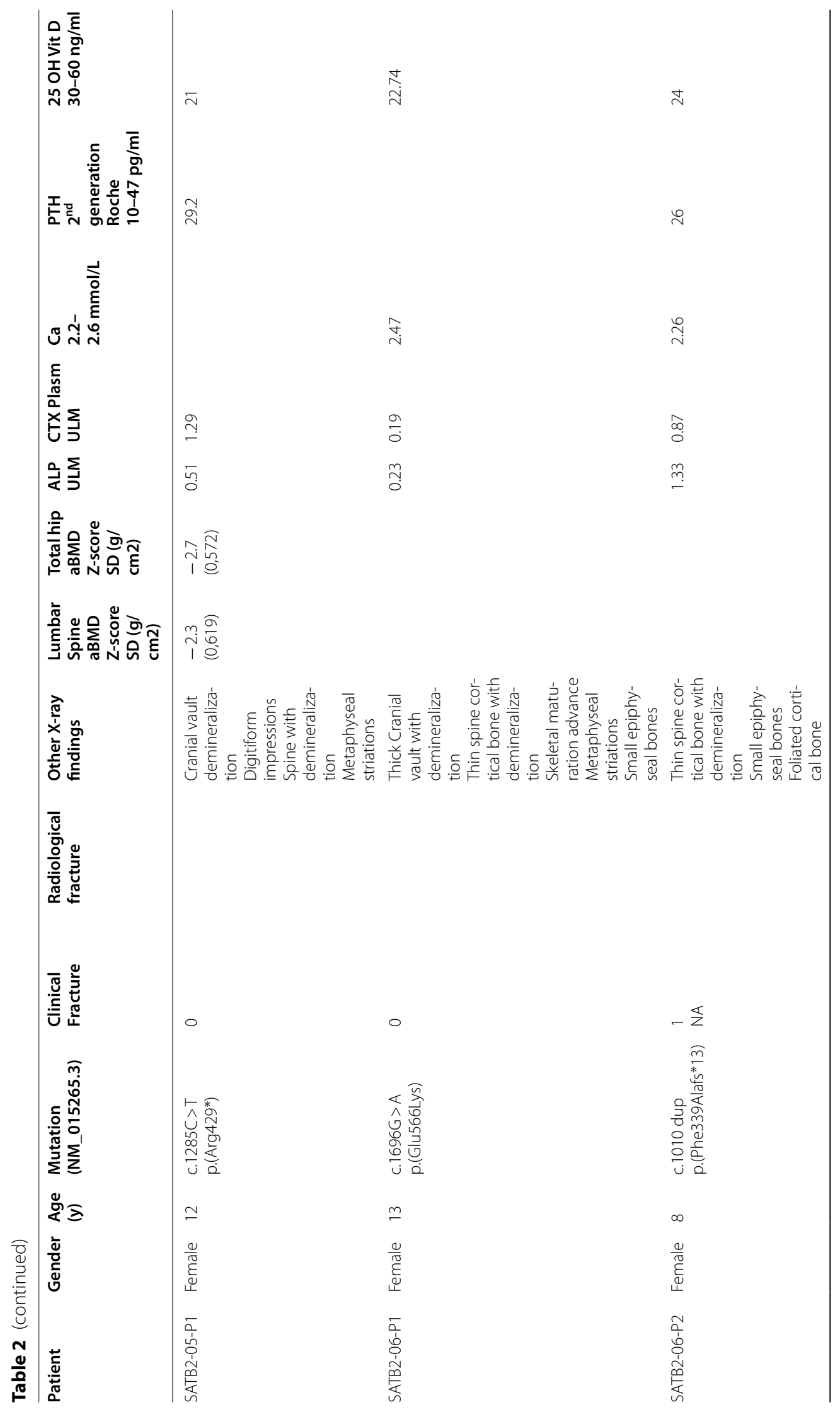




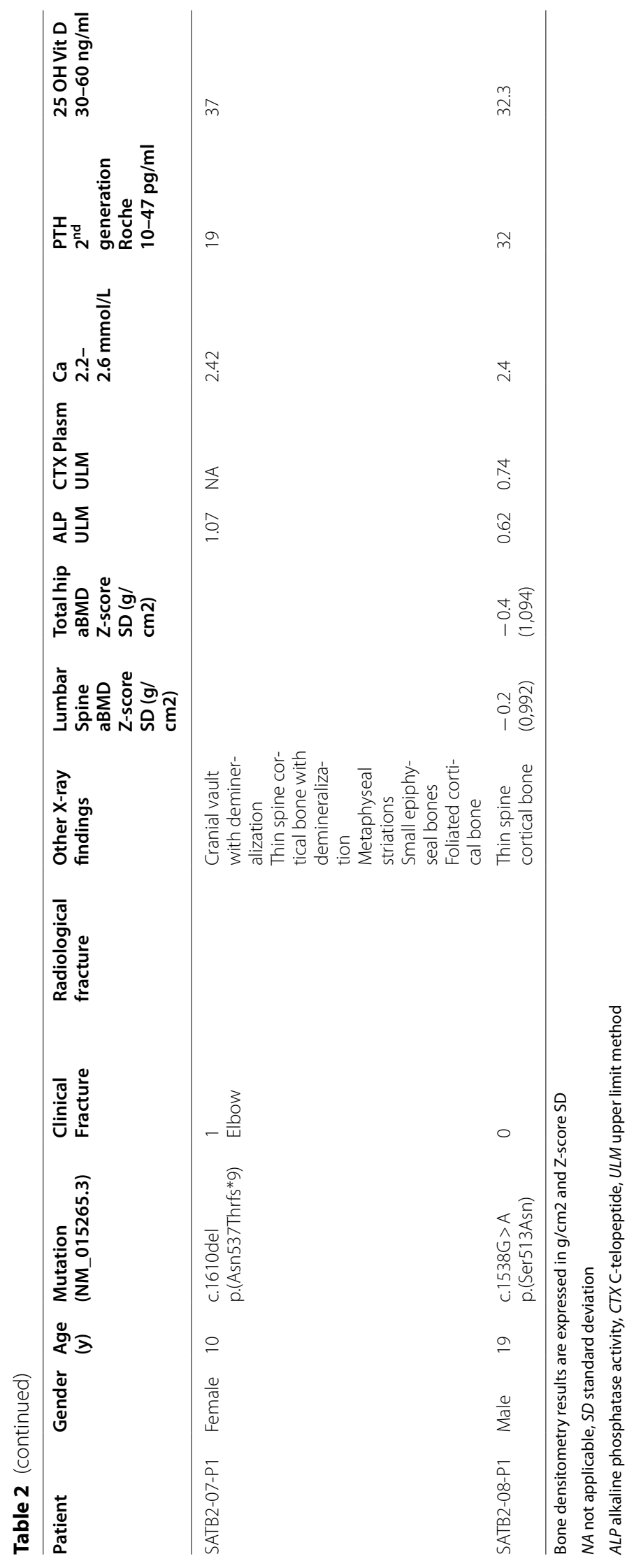


Table 3 Skeletal characteristics of the SATB2 cohort

\begin{tabular}{|c|c|}
\hline \multicolumn{2}{|l|}{ SATB2 cohort, 19 patients } \\
\hline Age (years $\pm S D$ ) & $9.2(1-19$ years $)$ \\
\hline Female gender $(\mathrm{N}, \%)$ & 9/19 (47\%) \\
\hline Clinically reported fractures (N, \%) & 9/19 (47\%) \\
\hline \multicolumn{2}{|l|}{ Radiological fracture $(\mathrm{N}, \%)$} \\
\hline Fragility fracture $(\mathrm{N}, \%)$ & $6 / 17(35 \%)$ \\
\hline \multicolumn{2}{|c|}{ Low bone mineral density at the lumber spine or total hip ( $N, \%)$} \\
\hline$(Z$-score $\leq-2.0 \mathrm{SD})$ & $7 / 17(41 \%)$ \\
\hline \multicolumn{2}{|c|}{ Fragility fracture and/or Low bone mineral density } \\
\hline$(Z$-score $\leq-2.0 \mathrm{SD})(\mathrm{N}, \%)$ & $11 / 17(65 \%)$ \\
\hline \multicolumn{2}{|l|}{ X-ray findings } \\
\hline \multicolumn{2}{|l|}{ Calvaria } \\
\hline Digitiformes Impressions ( $\mathrm{N}, \%)$ & $8 / 14(57 \%)$ \\
\hline Demineralization ( $N, \%)$ & 10/14 (71\%) \\
\hline \multicolumn{2}{|l|}{ Spine } \\
\hline Vertebral compression fracture (N, \%) & $6 / 17(35 \%)$ \\
\hline Cortical fine (N, \%) & 15/17 (85\%) \\
\hline Demineralization ( $N, \%)$ & $16 / 17(94 \%)$ \\
\hline \multicolumn{2}{|l|}{ Tubularbones } \\
\hline Demineralization ( $N, \%)$ & 18/19 (95\%) \\
\hline Streak metaphysis (N, \%) & $13 / 19(68 \%)$ \\
\hline Small epiphysis (N,\%) & $12 / 19(63 \%)$ \\
\hline Cortical foliated (N, \%) & 15/19 (79\%) \\
\hline Cortical thick (N, \%) & $7 / 19(37 \%)$ \\
\hline \multicolumn{2}{|l|}{ Hands } \\
\hline Distal phalanges shortened and widened (N, \%) & $7 / 16(43 \%)$ \\
\hline \multicolumn{2}{|l|}{ aBMD } \\
\hline Lumbar spine Z-score (mean, SD) & $-1.81 \pm 1.26$ \\
\hline Total hip Z-score (mean, SD) & $-1.37 \pm 0.94$ \\
\hline \multicolumn{2}{|l|}{ Biochemical findings } \\
\hline Total Serum Calcium (2.20-2.60, mean, \pm SD) & $2.41 \pm 0.11$ \\
\hline Serum Phosphate (mean, \pm SD) & $1.55 \pm 0.35$ \\
\hline Ionized Calcium (1.1-1.3 mmol/L) & $1.24 \pm 0.04$ \\
\hline $25 \mathrm{OH}$ Vit D (30-60 ng/ml) & $27.2 \pm 8.1 S D$ \\
\hline 1,25 OH Vit D (30-80 ng/l) & $64.96 \pm 20.0 S D$ \\
\hline $\operatorname{ALP}(U I / L)^{*}$ & $\begin{array}{l}366.89 \pm 114 \text { SD } \\
(0.86 \pm 0.28 \text { ULM })\end{array}$ \\
\hline Osteocalcin (microg/l)* & 92.40 (1.11 ULM) \\
\hline $\operatorname{P} 1 N P(n g / m l)^{*}$ & 964.21 (1.65 ULM) \\
\hline CTX $(p m o l / l)^{*}$ & 14221 (0.79 ULM) \\
\hline PTH $(10-50 \mathrm{pg} / \mathrm{ml})$ & 34 (0.74 ULM) \\
\hline
\end{tabular}

$\mathrm{X}$ Ray results as a percentage of a number of subjects. For DMO, results are given by the mean in $\mathrm{g} / \mathrm{cm}^{2}$ and SD. For biological results, the mean of the measurements are given. For data whose reference ranges vary with age, we also calculated ULM (Upper Limit Method)

*For normal range, please refer to Additional files. Reference values are presented by age and gender. Section headings are in bold

had at least one vertebral compression fracture on X-ray findings; and 11 patients (65\%) had a fragility fracture and/or aBMD Z-score $\leq-2 \mathrm{SD}$. The prevalence of osteoporosis defined by at least one vertebral compression

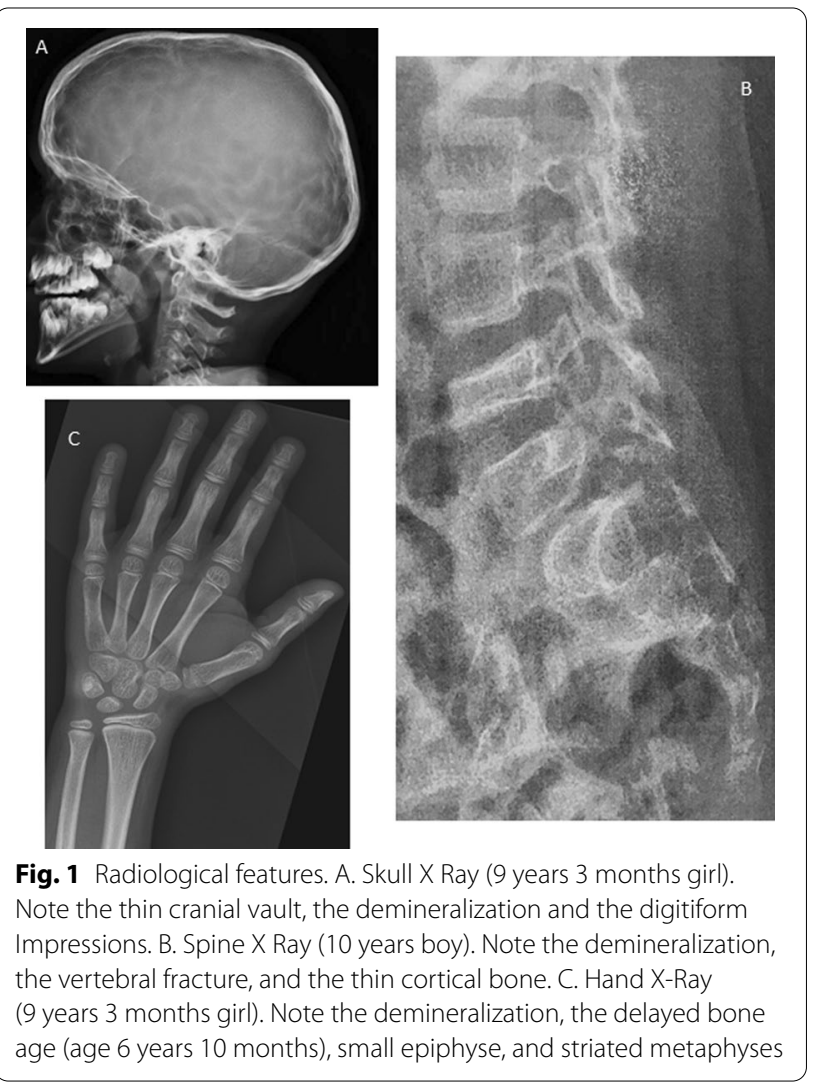

fracture, or by the presence of both a clinically significant fracture history and a BMD Z-score $\leq-2.0 \mathrm{DS}$, was of $8 / 17(47 \%)$.

\section{Biological evaluation (Tables 2, 3 and Additional file: Tables)}

Serum total calcium, ionized calcium and serum phosphate were in the normal range in all patients. $25 \mathrm{OH}$ Vitamin D value was below $30 \mathrm{ng} / \mathrm{ml}$ in $12 / 18$ patients (66.7\%), with a mean value of $27.2 \pm$ SD $8.12 \mathrm{ng} / \mathrm{mL}$. Parathyroid hormone (PTH) was above normal in 3 patients and in the normal range in most patients: $34.0 \pm \mathrm{SD}$ $14.42 \mathrm{pg} / \mathrm{ml}, \min 19.0, \max 68.2(10-50 \mathrm{pg} / \mathrm{ml})$, ie 0.74 ULM (Upper Limit Multiple) [11]. CTX levels were in the upper normal values when using reference range values adapted to the patient age: $14.221 \pm \mathrm{SD} 435 \mathrm{pmol} / \mathrm{L}$, min 3364, max 18.832, (7.000-18.000 pmol / L), ie 0.79 ULM. Alkaline phosphatases (ALP) were above normal values in 10/17 patients (59\%). Among patients with increased ALP values, $7 / 10$ (70\%) had a history of fractures but $30 \%$ had no history of clinical or radiological fracture. Osteocalcin and P1NP were both above normal values: $92.4 \pm$ SD 34.7 microg / L, $\min 43.9, \max 147$ (38-83 microg / L), ie 1.11 ULM and $964.2 \pm 381.8 \mathrm{ng} / \mathrm{ml}$ standard function of age, 1.65 ULM, respectively. 


\section{Biochemical parameters and bone mineral density correlations (Table 4)}

We next assessed whether bone mass was correlated with biochemical parameters. Hip BMD was positively correlated with spine BMD. Markers of bone formation (ALP and osteocalcin) were positively correlated with resorption markers (CTX) suggesting bone coupling between bone formation and bone resorption in patients with SAS. Bone formation marker ALP was positively correlated with P1NP and tended to be correlated with osteocalcin $(p=0.0676)$.

\section{Comparison of fractured with non-fractured SATB2 patients}

ALP, assessed using the ULM levels, were significantly higher in individuals with pathogenic variants in SATB2 with a history of fracture compared to non-fractured patients $(p=0.01)$.

\section{Discussion}

We report here the investigation of skeletal manifestations in a cohort of patients with SATB2 variants. The SAS clinical spectrum described so far, has mainly focused on teeth abnormalities, developmental delay, speech limitations and behavioral issues. The aim of the study was to highlight the skeletal phenotype pertaining to premature osteoporosis. Indeed, we observed a particularly high frequency of fractures and low bone mass in these patients with $35 \%$ of radiologic vertebral compression fractures. Importantly, the frequency of vertebral compression fractures was very much underestimated with only one patient reporting vertebral fracture whereas 6/17 (35\%) patients displayed radiographic vertebral fractures. Additionally, $54 \%$ of patients showed evidence of low bone mass as defined by a Z-score below $-2 \mathrm{SD}$.

Furthermore, the extensive radiological assessment of this cohort allows the description of unreported skeletal features including thin cortical bone, dysmorphic phalanges, and delayed carpal ossification.

The systematic biochemical assessment, performed independently of any fracture event, led to the observation of increased ALP levels in more than half the cohort (59\%), using age adjusted reference range, as well as increased osteocalcin and P1NP levels, all known markers of bone formation. These findings support that the abnormalities in bone formation markers are the result of the underlying bone disease rather than related to a fracture event. We also observed a correlation between P1NP and ALP levels, in accordance with the increase in bone formation markers. These findings are consistent with previous report of increased ALP and/or P1NP and and/ or osteocalcin in a very limited number of patients with SAS $[1,9]$. Finally, we also found increased CTX levels, which were correlated with increased bone formation markers, supporting increased bone turnover in these patients [1].

The exact mechanism contributing to the skeletal phenotype remains incompletely understood. Bone formation markers are the products of active osteoblasts expressed during different phases of their development and considered to reflect different aspects of osteoblast function and bone formation. SATB2 regulates skeletogenesis by modulating the expression of osteoblast specific genes like SOX9, ATF4 or RUNX2, and plays a role in the differentiation of osteoblasts [9]. Moreover, it has been also demonstrated that mutations in SATB2 reduce pre-osteoblast formation supporting that SATB2

Table 4 Correlation between BMD and biological parameters

\begin{tabular}{|c|c|c|c|c|c|c|c|}
\hline Hip BMD Z-score & Spine BMD Z-score & Phosphate & lonized calcium & ALP & CTX & Osteocalcin & P1NP \\
\hline \multicolumn{8}{|l|}{ ALP } \\
\hline $\begin{array}{l}R=0.334 \\
P=0.665\end{array}$ & $\begin{array}{l}\mathrm{R}=0.933 \\
P=0.0204\end{array}$ & & $\begin{array}{l}R=-0.008 \\
P=0.9792\end{array}$ & & $\begin{array}{l}\mathrm{R}=0.967 \\
P=0.0331\end{array}$ & $\begin{array}{l}R=0.779 \\
P=0.0676\end{array}$ & $\begin{array}{l}\mathrm{R}=0.687 \\
P=0.0066\end{array}$ \\
\hline \multicolumn{8}{|l|}{ CTX } \\
\hline $\begin{array}{l}R=-0.302 \\
P=0.4289\end{array}$ & $\begin{array}{l}R=0.254 \\
P=0.4793\end{array}$ & $\begin{array}{l}R=0.448 \\
P=0.1251\end{array}$ & $\begin{array}{l}R=0.387 \\
P=0.2141\end{array}$ & $\begin{array}{l}\mathrm{R}=0.967 \\
P=0.0331\end{array}$ & & $\begin{array}{l}\mathrm{R}=0.678 \\
P=0.0077\end{array}$ & $\begin{array}{l}\mathrm{R}=0.549 \\
P=0.0421\end{array}$ \\
\hline \multicolumn{8}{|l|}{ Osteocalcin } \\
\hline $\begin{array}{l}R=-0.475 \\
P=0.1649\end{array}$ & $\begin{array}{l}\mathrm{R}=-0.616 \\
P=0.0331\end{array}$ & $\begin{array}{l}R=0.044 \\
P=0.8759\end{array}$ & $\begin{array}{l}R=0.061 \\
P=0.8346\end{array}$ & $\begin{array}{l}R=0.779 \\
P=0.0676\end{array}$ & $\begin{array}{l}\mathrm{R}=0.678 \\
P=0.0077\end{array}$ & & $\begin{array}{l}R=0.315 \\
P=0.2525\end{array}$ \\
\hline \multicolumn{8}{|l|}{ P1NP } \\
\hline $\begin{array}{l}\mathrm{R}=-0.950 \\
P=0.0132\end{array}$ & $\begin{array}{l}R=0.585 \\
P=0.0588\end{array}$ & $\begin{array}{l}\mathrm{R}=0.847 \\
P=0.0001\end{array}$ & $\begin{array}{l}R=-0.141 \\
P=0.6466\end{array}$ & $\begin{array}{l}\mathrm{R}=0.687 \\
P=0.0066\end{array}$ & $\begin{array}{l}\mathrm{R}=0.549 \\
P=0.0421\end{array}$ & $\begin{array}{l}R=0.268 \\
P=0.3349\end{array}$ & \\
\hline
\end{tabular}

Note that hip BMD is positively correlated with albuminemia and spine BMD, whereas it is negatively correlated with bone formation parameters osteocalcin and $\mathrm{P} 1 \mathrm{NP}$, and phosphate levels. Spine BMD is positively correlated with ionized calcium and ALP, and negatively correlated with osteocalcin. CTX is positively correlated with osteocalcin and ALP. Osteocalcin is positively correlated with CTX and negatively with spine BMD. P1NP is positively correlated with ALP. BMD is negatively correlated with markers of bone formation. Significant correlations are in bold 
also regulates progenitor proliferation and participates in both proliferation and differentiation processes [12].

Although this study has limitations, including the small size of the cohort, and the difficulties in the interpretation of the bone markers values in children, related to age variability, it clearly highlights the broad spectrum of skeletal abnormalities, fractures and low bone mass in individuals with SAS. This study also supports the need for regular assessment of BMD and bone turnover markers in the management of patients with SATB2 pathogenic variants. While none of the individuals reported here had any specific treatment apart from vitamin D supplementation, the role of SATB2 in osteoblast differentiation and proliferation may also suggest the use of anabolic agent targeting osteoblast. For this reason, we did not introduce bisphosphonates in this cohort. Furthermore, detecting any additional risk factor for osteoporosis and/or fractures, including vitamin D insufficiency, may help to prevent fractures in this context.

\section{Supplementary Information}

The online version contains supplementary material available at https://doi. org/10.1186/s13023-022-02229-5.

Additional file 1. References for normal biological values for children and adults.

Additional file 2. Raw data and ULM values for P1NP and Osteocalcin in the 19 patients.

Acknowledgements

We thank Farah LAWRENCE-WILDE for her help. We thank all the patients and their families.

\section{Authors' contributions}

VCD conceived of the study. MM collected all the data. MM and VCD analysed the data and wrote the manuscript. EK participated in the design of the study and performed the statistical analysis. AA, JA, YC, AG, CF, CM, CM, LP, CQ, $J V G, M R, V C D$ participated in the inclusion of patients. SB participated in the radiological analysis. GM participated in the BMD data analysis and MLP in the biological analysis. GB and VP participated in the molecular analysis. All authors read and approved the final manuscript.

\section{Funding}

No specific funding.

\section{Availability of data and materials}

The data are available in a local database and can be shared on request.

\section{Declarations}

\section{Ethics approval and consent to participate}

The study received approval from the committee for the protection of persons (CPP) on the 19/09/2017, file No 2017-102169-44, Reference CPP: 3534-NI. Data collection was in accordance with CNIL regulations and in accordance with the Helsinki declaration.

\section{Consent for publication}

Consent for publication were obtained either by the patient (if an adult) or at least by one of the parents or a legal representative if the patient was a minor.

\section{Competing interest}

The authors declare no conflict of interest.

\section{Author details}

${ }^{1}$ Clinical Genetics, Necker Enfants Malades Hospital, APHP, 149 rue de Sevres, Paris 75015, France. ${ }^{2}$ Department of Neonatal Medicine, Cochin-Port Royal Hospital, APHP, Paris, France. ${ }^{3}$ Department of Pediatric Radiology, Necker Enfants Malades Hospital, APHP, Paris, France. ${ }^{4}$ Functional Exploration Laboratory, Necker Enfants Malades Hospital, APHP, Paris, France. ${ }^{5}$ Sorbonne University, Reference Center for Intellectual Disabilities, Department of Genetics and Medical Embryology, Armand-Trousseau Hospital, APHP, Paris, France.

${ }^{6}$ Clinical Genetics Functional Unit, Robert Debré Hospital, APHP, Paris, France.

${ }^{7}$ Department of Clinical Genetics, Rouen, France. ${ }^{8}$ Clinical Genetics, ClermontFerrand CHU, Clermont-Ferrand, France. ${ }^{9}$ Paris Cité University, Reference Center for Constitutional Bone Diseases, INSERM UMR1163, Imagine Institute, Paris, France. ${ }^{10} \mathrm{Clinical}$ Genetics, La Pitié Salpétrière Hospital, APHP, Paris, France. ${ }^{11}$ Clinical Genetics, Hospital Sud, Rennes, France. ${ }^{12}$ Clinical Genetics, Hospital Pellegrin, Bordeaux, France. ${ }^{13}$ Molecular Genetics, Necker Enfants Malades Hospital, APHP, Paris, France. ${ }^{14}$ Reference Center for Skeletal Dysplasia, Cochin Hospital, APHP, Paris, France. ${ }^{15}$ Department of Physiology, Hôpital Necker Enfants Malades and Hôpital Européen Georges Pompidou, AP-HP, Paris, France.

Received: 20 July 2021 Accepted: 6 February 2022

Published online: 03 March 2022

\section{References}

1. Boone PM, Chan YM, Hunter JV, Pottkotter LE, Davino NA, Yang Y, et al. Increased bone turnover, osteoporosis, progressive tibial bowing, fractures, and scoliosis in a patient with a final-exon SATB2 frameshift mutation. Am J Med Genet A. 2016;170(11):3028-32.

2. Zarate YA, Fish JL. SATB2-associated syndrome: Mechanisms, phenotype, and practical recommendations. Am J Med Genet A [Internet]. 2017 [cité 13 mars 2018];173(2):327-37.

3. Zarate YA, Smith-Hicks CL, Greene C, Abbott M-A, Siu VM, Calhoun ARUL, et al. Natural history and genotype-phenotype correlations in 72 individuals with SATB2-associated syndrome. Am J Med Genet A. 132018

4. Zarate YA, Perry H, Ben-Omran T, Sellars EA, Stein Q, Almureikhi M, et al. Further supporting evidence for the SATB2-associated syndrome found through whole exome sequencing. Am J Med Genet A. 2015;167A(5):1026-32.

5. Leoyklang P, Suphapeetiporn K, Siriwan P, Desudchit T, Chaowanapanja P, Gahl WA, et al. Heterozygous nonsense mutation SATB2 associated with cleft palate, osteoporosis, and cognitive defects. Hum Mutat. 2007;28(7):732-8.

6. Guo Y, Dong S-S, Chen X-F, Jing Y-A, Yang M, Yan H, et al. Integrating epigenomic elements and GWASs Identifies BDNF gene affecting bone mineral density and osteoporotic fracture risk. Sci Rep. 2016;6:30558.

7. Zhang C. Molecular mechanisms of osteoblast-specific transcription factor Osterix effect on bone formation. Beijing Da Xue Xue Bao. 2012;44(5):659-65.

8. Xu R, Fu Z, Liu X, Xiao T, Zhang P, Du Y, et al. Transplantation of osteoporotic bone marrow stromal cells rejuvenated by the overexpression of SATB2 prevents alveolar bone loss in ovariectomized rats. Exp Gerontol. 2016:84:71-9.

9. Dobreva G, Chahrour M, Dautzenberg M, Chirivella L, Kanzler B, Fariñas I, et al. SATB2 is a multifunctional determinant of craniofacial patterning and osteoblast differentiation. Cell. 2006;125(5):971-86.

10. Zarate YA, Steinraths M, Matthews A, Smith WE, Sun A, Wilson LC, et al. Bone health and SATB2-associated syndrome. Clin Genet. 2018;93(3):588-94.

11. Brott DA. Are laboratory parameter (biomarker) values similar to the healthy volunteer reference range in all patient populations? - PubMed - NCBI. [cité 3 mars 2020]; Disponible sur: https://www.ncbi.nlm.nih.gov/ pubmed/30233139

12. Dowrey T, Schwager EE, Duong J, Merkuri F, Zarate YA, Fish JL. Satb2 regulates proliferation and nuclear integrity of pre-osteoblasts. Bone. 2019;127:488-98. 


\section{Publisher's Note}

Springer Nature remains neutral with regard to jurisdictional claims in published maps and institutional affiliations.

- fast, convenient online submission

- thorough peer review by experienced researchers in your field

- rapid publication on acceptance

- support for research data, including large and complex data types

- gold Open Access which fosters wider collaboration and increased citations

- maximum visibility for your research: over $100 \mathrm{M}$ website views per year

At BMC, research is always in progress.

Learn more biomedcentral.com/submissions 